УДК 550.41

\title{
КОЭФФИЦИЕНТЫ РАСПРЕДЕЛЕНИЯ РЗЭ+Ү МЕЖДУ МИНЕРАЛАМИ И ОХЛАЖДАЮЩИМСЯ БОГАТЫМ СУЛЬФАТНОЙ СЕРОЙ ФЛЮИДОМ (ТЕРМОДИНАМИЧЕСКОЕ МОДЕЛИРОВАНИЕ)
}

\author{
Широносова Галина Петровна', \\ shiron@igm.nsc.ru \\ Прокопьев Илья Романович ${ }^{12}$, \\ prokop@igm.nsc.ru

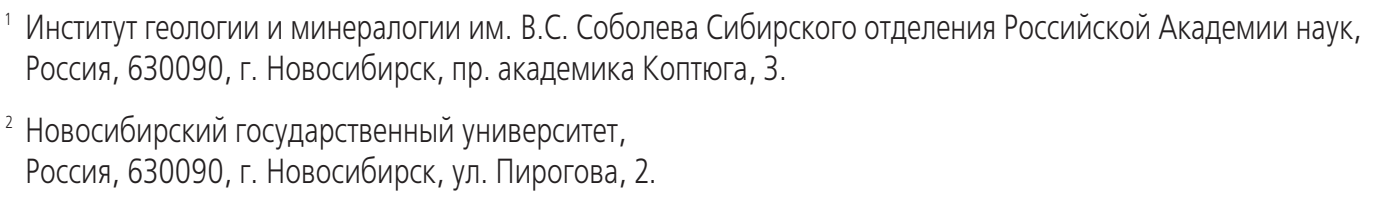

Актуальность работы обусловлена тем, что изучение коэффициентов распределения РЗЭ+Ү между минералами-концентраторами этих элементов и между минералами и сульфатными флюидами в различных щелочных и слабокислых системах позволяет получить недостающие параметры, необходимые для моделирования процессов кристаллизации и рудогенеза в пределах карбонатитовых рудно-магматических систем. Для определения механизмов концентрирования рудных компонентов важнейшим является выявление главных и второстепенных минералов-концентраторов редких элементов.

Цель работы: оценить коэффициенты распределения лантаноидов +Y между РЗЭ-содержащими минералами и между этими минералами и равновесными с ними гидротермальными флюидами в слабокислых и слабощелочных условиях при температуре 500-100 ㄷ и давлении 2000-125 бар.

Методы: термодинамическое моделирование взаимодействия монацита и кальцита с гидротермальными флюидами с применением программного комплекса НСh (разработчик Ю.В. Шваров). Для определения состояния равновесия в алгоритме программы использован метод минимизации свободной энергии Гиббса системы (программа GIBBS) в комплексе с базой термодинамических данных UNITHERM.

Результаты. Показано, что коэффициенты распределения РЗЭ+Ү между минералами большей частью не зависят от кислотнощелочной обстановки минералообразования. Кислотность-щелочность флюидов заметно сказывается только на распределении РЗЭ между флюоритом и фторапатитом. Основное влияние на фракционирование РЗЭ оказывает температура и сопряженные с нею параметры. Только для пары монацит/РЗЭ-флюорит понижение температуры способствует росту величин коэффициентов распределения, т. е. вхождению РЗЭ в монацит. В парах монацит/РЗЭ-фторапатит, ксенотим/РЗЭ-фторапатит и в кислых условиях в паре РЗЭ-флюорит/РЗЭ-фторапатит понижение температуры сопровождается уменьшением величин коэффициентов распределения и способствует некоторому обогащению фторапатита редкими землями. Кd минерал/флюид для монацита, ксенотима и РЗЭ-флюорита выше единицы и это означает, что при охлаждении равновесного флюида РЗЭ+Ү преимущественно концентрируются в этих минералах.

\section{Ключевые слова}

РЗЭ, монацит, ксенотим, РЗЭ-фторапатит, РЗЭ-флюорит, коэффициенты распределения РЗЭЭҮ, окисленный флюид, термодинамическое моделирование.

Редкоземельные элементы (РЗЭ) играют важную роль в экономике, особенно в быстро развивающихся инновационных отраслях промышленности. Основными источниками промышленного получения РЗЭ являются коры выветривания гранитов, карбонатитовые месторождения и прибрежно-морские россыпи. В группу РЗЭ входят лантаноиды, представляющие собой ряд химических элементов от ${ }_{57} \mathrm{La}$ до ${ }_{71} \mathrm{Lu}$. Их ионный радиус постепенно уменьшается с увеличением атомного номера, хотя их химические свойства близки. РЗЭ обычно встречаются в естественной среде как трехвалентные ионы. Однако в окислительной среде, такой как поверхностные воды, Се может существовать как четырехвалентный ион, так и в виде минерала церианита $\left(\mathrm{CeO}_{2}\right)$ [1-3], тогда как $\mathrm{Eu}$ и $\mathrm{Yb}$ могут встречаться в двухвалентном состоянии при восстановительных условиях. Редкоземельные элементы представляют особый интерес для геохимии из-за их использования в качестве химических индикаторов природных процессов. Сход- ная электронная конфигурация РЗЭ обуславливает их относительно сходное химическое поведение, но постепенно изменяющийся ионный радиус с увеличением номера лантаноида, однако приводит к различной концентрации РЗЭ из-за их индивидуального комплексообразования в гидротермальных средах и изменения их способности встраиваться в твердые фазы [4].

Достижения в аналитической химии позволяют определить концентрацию многих микроэлементов и их изотопов в горных породах. Благодаря достижениям в микроанализе микроэлементов теперь можно экспериментально определить коэффициенты распределения для геодинамических условий, например, при плавлении коры и мантии $[5,6]$. Полученный большой объем экспериментальных данных может быть использован в качестве основы для количественных моделей распределения микроэлементов в зависимости от давления, температуры и окислительно-восстановительного потенциала системы [7]. Например, со- 
держание РЗЭ в карбонатных минералах использовалось для отслеживания их потоков от континентов и до океанической коры; экспериментально определенные коэффициенты распределения между кальцитом и водным раствором, близким к морской воде, были опубликованы в [8]. Другие исследования направлены на выяснение вхождения европия в кальцит, поскольку Еu считается аналогом для долгоживущих трехвалентных актинидов, в частности $\mathrm{Am}$ (III) и $\mathrm{Cm}$ (III), которые представляют интерес для нейтрализации ядерных отходов $[9,10]$

Равновесное распределение элемента между двумя материалами может быть охарактеризовано коэффициентом распределения, который описывается отношением концентрации данного элемента между двумя материалами. Концентрация элемента может быть определена несколькими разными способами [11], и поэтому существует несколько определений коэффициента распределения. В большинстве литературных источников по геохимии концентрация элемента измеряется весовой долей (во многих случаях оксидами) и используется коэффи- циент распределения Нернста, который определяется формулой: $\mathrm{D}_{\mathrm{i}}^{\mathrm{Y} / \mathrm{X}}=\mathrm{C}_{\mathrm{i}}^{\mathrm{Y}} / \mathrm{C}_{\mathrm{i}}^{\mathrm{X}}$, где $\mathrm{C}_{\mathrm{i}}^{\mathrm{Y}(\mathrm{X})}$ - массовая доля элемента і в фазе Y (или X) [8, 12, 13]. Вместо массовой доли можно использовать мольную долю для определения коэффициента распределения, $\mathrm{D}_{\mathrm{i}}^{\mathrm{Y} / \mathrm{X}}=\mathrm{C}_{\mathrm{i}}^{\mathrm{Y}} / \mathrm{C}_{\mathrm{i}}^{\mathrm{X}}$, где $\mathrm{C}_{\mathrm{i}}^{\mathrm{Y}(\mathrm{X})}$ - мольная доля элемента і в фазе $\mathrm{Y}$ (или $\mathrm{X})[14,15]$, а также $\mathrm{K}_{\mathrm{i}}^{\mathrm{Y}} \mathrm{x}^{\mathrm{X}}=\mathrm{a}_{\mathrm{i}}{ }^{\mathrm{Y}} / \mathrm{a}_{\mathrm{i}}^{\mathrm{X}}$, где $\mathrm{a}_{\mathrm{i}}^{\mathrm{Y}(\mathrm{X})}$ активность элемента і в фазе $\mathrm{Y}(\mathrm{X})$, например [16].

В настоящей работе в основном оценивались мольные коэффициенты распределения РЗЭ между минералами: монацит/РЗЭ-флюорит и РЗЭ-фторапатит, ксенотим/РЗЭ-фторапатит, РЗЭ-флюорит/РЗЭ-фторапатит, находящимися в равновесии со слабощелочным и слабокислым охлаждающимися флюидами сложного состава. Кроме того, оценены массовые коэффициенты распределения РЗЭ между указанными минералами для щелочного варианта флюида. Массовые коэффициенты также использованы для оценки распределения РЗЭ между указанными минералами и флюидом в слабощелочном варианте. Данное исследование является продолжением предыдущей работы [17], где детально описано соотношение РЗЭ-содержа-

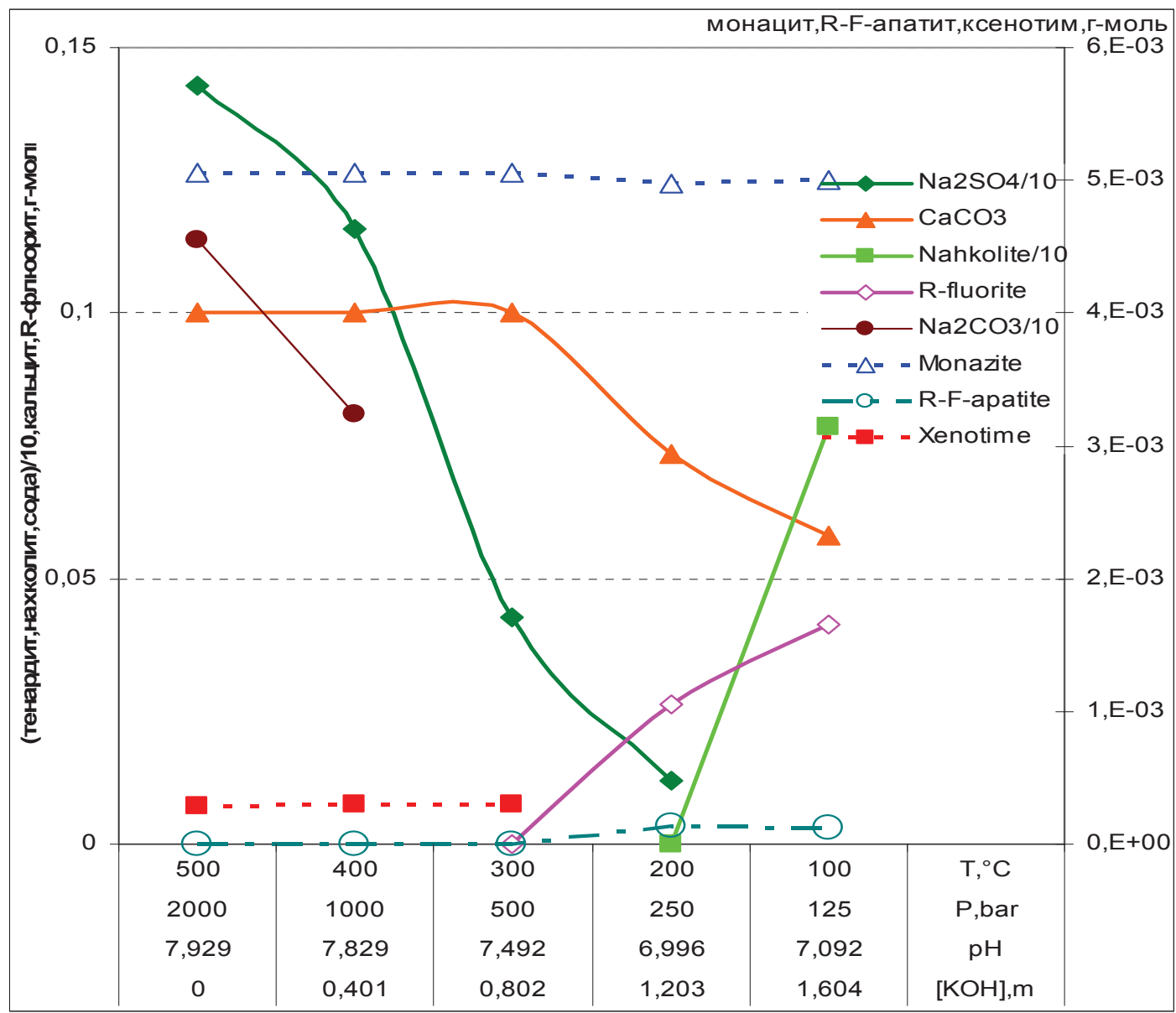

Рис. 1. Соотношение равновесных твердых фаз в зависимости от параметров слабощелочного рудообразующего флюида: [0,1 г-моль $\mathrm{CaCO}_{3}+0,0053$ г-моль монацита $]_{\mathrm{\tau в}}+1 \mathrm{~m} \mathrm{NaCl}+5 \mathrm{~m} \mathrm{NaHCO}_{3}+2 \mathrm{~m} \mathrm{Na}_{2} \mathrm{SO}_{4}+0,1 \mathrm{~m} \mathrm{HF+0,1} \mathrm{m} \mathrm{H}_{2} \mathrm{~S}+1,5 \mathrm{~m} \mathrm{HCl}+$ $+(0,401 i) \mathrm{m} \mathrm{KOH}+1 \mathrm{Kг} \mathrm{H}_{2} \mathrm{O}$, где i - шаг расчета $\left(0-500{ }^{\circ} \mathrm{C}, 2000\right.$ бар; $4-100{ }^{\circ} \mathrm{C}, 125$ бар)

Fig. 1. Relationship of equilibrium solid phase as a function of the parameters of a weakly alkaline ore-forming fluid: $[0,1$ mole $\mathrm{CaCO}_{3}+0,0053$ mole monazite] $]_{\text {solid }}+1 \mathrm{~m} \mathrm{NaCl}^{\circ} \mathrm{m} \mathrm{NaHCO}_{3}+2 \mathrm{~m} \mathrm{Na}_{2} \mathrm{SO}_{4}+0,1 \mathrm{~m} \mathrm{HF}^{2} 0,1 \mathrm{~m} \mathrm{H}_{2} \mathrm{~S}+1,5 \mathrm{~m} \mathrm{HCl}+(0,401 i) \mathrm{m} \mathrm{KOH}+1 \mathrm{~kg}$ $\mathrm{H}_{2} \mathrm{O}$, where $i$ is the calculation step $\left(0-500{ }^{\circ} \mathrm{C}, 2000\right.$ bar; $4-100{ }^{\circ} \mathrm{C}, 125$ bar) 
щих минералов в равновесных ассоциациях, условия проведения расчетов и источники термодинамических данных. В настоящей работе приведены два основополагающих рисунка из этой статьи по распределению устойчивых твердых фаз, именно тех вариантов, для которых проведен расчет соответствующих коэффициентов распределения. Как уже отмечалось в работе [17], термодинамические расчеты проведены с использованием программного пакета $\mathrm{HCh}[18,19]$, который позволяет рассчитывать составы сосуществующих твердых растворов, выраженные в мольных долях соответствующего лантаноида, а также количество каждого равновесного минерала и состав равновесного флюида. Несложный пересчет позволяет перейти от мольных коэффициентов распределения РЗЭ к их массовым величинам.

\section{Распределение Р3Э+Ү между минералами \\ Слабощелочной вариант}

Во всем исследованном интервале параметров сосуществуют монацит и РЗЭ-рторапатит (рис. 1), поэтому представляет интерес проследить коэффициенты распределения легких РЗЭ между этими минералами (рис. 2) по отношению в них мольных долей $\mathrm{X}$ каждого РЗЭ $\left(\mathrm{Kd}_{\mathrm{X}}=\mathrm{X}_{\mathrm{Ln}}\right.$ в монаците $/ \mathrm{X}_{\mathrm{Ln}}$ в РЗЭ-фторапатите). Все коэффициенты оказываются больше десяти, т. е. все легкие РЗЭ предпочтительнее концентрируются в монаците, при этом величины коэффициентов монотонно уменьшаются с понижением температуры. Обращает на себя внимание тот факт, что более тяжелые РЗЭ имеют большие величины коэффициентов, т. е. они предпочтительнее уходят в монацит, а не в РЗЭ-фторапатит. При этом наблюдается следующий порядок величин коэффициентов: $\mathrm{Eu}>\mathrm{Gd}>=\mathrm{Sm}>\mathrm{Pr}>\mathrm{Nd}>\mathrm{La}>\mathrm{Ce}$.

Отметим, что церий - РЗЭ с самым высоким исходным содержанием в системе (т. е. в исходном монаците), оказывается в самом конце этой цепочки, а европий, имеющий самую низкую заданную концентрацию в системе, больше других РЗЭ предпочитает оставаться в монаците. В целом наблюдается последовательность величин коэффициентов распределения РЗЭ, соответствующая исходным их концентрациям, а не атомным номерам: чем меньше исходная концентрация элемента, тем предпочтительнее он остается в монаците.

В области высоких температур $\left(500-300{ }^{\circ} \mathrm{C}\right)$ с РЗЭ-фторапатитом сосуществует ксенотим, поэтому целесообразно рассмотреть распределение между этими минералами тяжелых РЗЭ. Все коэффициенты оказываются больше 100 , т. е. все тяжелые РЗЭ предпочтительнее концентрируются в ксенотиме, а не в РЗЭ-фторапатите при этом величины коэффициентов монотонно понижаются с понижением температуры, их зависимости от нее представляют собой ряд прямых параллельных линий и имеют практически линейный характер. Прослеживается следующий ряд величин коэффициентов: $\mathrm{Lu}>\mathrm{Yb}>\mathrm{Tb} \geq \mathrm{Er}>\mathrm{Dy}>\mathrm{Y}$, которые колеблются в интервале $2,85 \mathrm{E}+10>\mathrm{Kd}_{\mathrm{x}}>100$. При этом наиболее тяжелые РЗЭ предпочтительнее концентрируются в ксенотиме, хотя снова наблюдается зависимость коэффициентов распределения от концентрации их в исходном составе системы. Так, коэффициенты иттрия с более высоким исходным содержанием в системе по сравнению с другими элементами этой группы оказываются са-

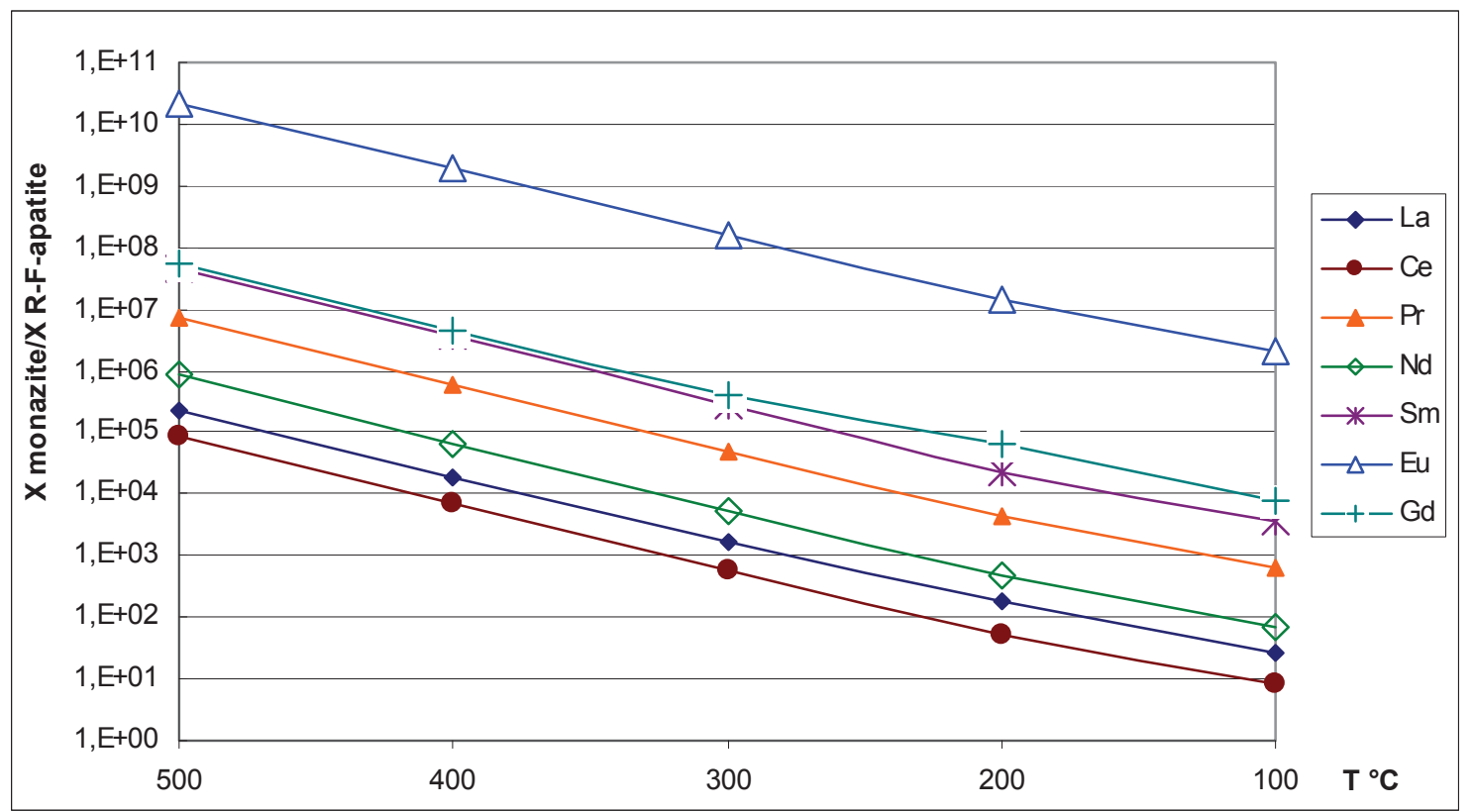

Рис. 2. Мольные коэффициенты распределения легких РЗЭ между монацитом и РЗЭ-фторапатитом в зависимости от температуры (и сопряженных с ней параметров (рис. 1))

Fig. 2. Molar coefficients of light REE distribution between monazite and REE-fluorapatite as a function of temperature (and the parameters associated with it (Fig. 1)) 
мыми низкими, а лютеция (с наименьшим исходным содержанием в системе) - самыми высокими. Таким образом, и монацит, и ксенотим с понижением температуры легче отдают свои РЗЭ фторапатиту.

В области низких параметров флюида $\left(300-100{ }^{\circ} \mathrm{C}\right)$ появляется РЗЭ-флюорит, сосуществующий с монацитом и РЗЭ-фторапатитом. Все коэффициенты распределения легких РЗЭ между монацитом и РЗЭ-флюоритом имеют положительные величины $\left(17<\mathrm{Kd}_{\mathrm{x}}<8,3 \cdot 10^{+6}\right)$, т. е. все легкие РЗЭ «предпочитают» входить в монацит. При этом величины коәффициентов возрастают с понижением температуры, и линии их зависимости от температуры имеют вогнутый характер с легким изгибом при $200{ }^{\circ} \mathrm{C}$. Порядок возрастания величин коэффициентов следующий: $\mathrm{Gd}<\mathrm{La}<\operatorname{Pr}<\mathrm{Ce}<\mathrm{Nd}<\mathrm{Eu}<\mathrm{Sm}$, и, как видно из этого ряда, он не определяется ни исходными концентрациями, ни атомным номером РЗЭ.

На рис. 3 представлены коэффициенты распределения всех РЗЭ (кроме гольмия) между флюоритом и фторапатитом в области их сосуществования 300-100 ․ С. Для тяжелых РЗЭ линии величин зависимости коэффициентов распределения от температуры (и сопряженных с ней параметров флюида (рис.1)) показаны пунктирными линиями. Все коэффициенты тяжелых РЗЭ выше единицы (кроме иттербия при $\left.200-100{ }^{\circ} \mathrm{C}\right)$, т. е. они предпочтительнее входят в РЗЭ-флюорит, и только иттербий наряду с некоторыми легкими РЗЭ имеет коэффициенты ниже единицы, т. е. легче входят в РЗЭ-фторапатит. Наблюдается следующий порядок для элементов с $\mathrm{Kd}_{\mathrm{x}}<1: \mathrm{Yb}\left(200-100{ }^{\circ} \mathrm{C}\right)<\mathrm{Ce}\left(300-100{ }^{\circ} \mathrm{C}\right)<\mathrm{Nd}$ $\left(300-100{ }^{\circ} \mathrm{C}\right)<\operatorname{Sm}\left(200-100{ }^{\circ} \mathrm{C}\right)<\left(\mathrm{La}<\operatorname{Eu}\left(100{ }^{\circ} \mathrm{C}\right)\right)$, именно эти РЗЭ в указанных условиях сосредотачиваются во фторапатите. В целом практически все легкие РЗЭ по сравнению с тяжелыми имеют более низкие коэффициенты распределения между РЗЭ-флюоритом и РЗЭ-фторапатитом, т. е. из этих двух минералов флюорит является носителем тяжелых РЗЭ, а фторапатит - легких и иттербия. Наблюдается резко различная зависимость коэффициентов от температуры для легких и тяжелых РЗЭ: для легких почти линейное монотонное уменьшение при понижении температуры; для иттрия и всех тяжелых (кроме иттербия) кривые зависимости от температуры имеют выпуклый характер: от 300 к $200{ }^{\circ} \mathrm{C}$ наблюдается рост коэффициентов распределения, а при понижении температуры до $100{ }^{\circ} \mathrm{C}$ происходит их уменьшение, только для тербия и лютеция коэффициенты остаются на уровне величин при $200{ }^{\circ} \mathrm{C}$. Особняком стоит иттербий: его кривая имеет вогнутый характер, и если при $300{ }^{\circ} \mathrm{C}$ он предпочитает оставаться во флюорите $\left(\right.$ его $\mathrm{Kd}_{\mathrm{x}}$ около 100), то в интервале $200-100{ }^{\circ} \mathrm{C}$ его коэффициент понижается до $10^{-3}-10^{-5}$ соответственно, т. е. здесь он концентрируется во фторапатите.

\section{Слабокислый вариант}

На рис. 4 приведено соотношение равновесных твердых фаз в зависимости от параметров слабокислого рудообразующего флюида. Здесь при температуре $500-400{ }^{\circ} \mathrm{C}$ из редкоземельных минералов присутствуют только монацит - носитель легких и средних до гадолиния РЗЭ, и ксенотим - носитель иттрия и тяжелых РЗЭ. Монацит с РЗЭ-фторапатитом сосуществуют только в интервале $300-100{ }^{\circ} \mathrm{C}$. Несмотря на изменение $\mathrm{pH}$ флюида, характер, порядок и даже величины коэффициентов распределения

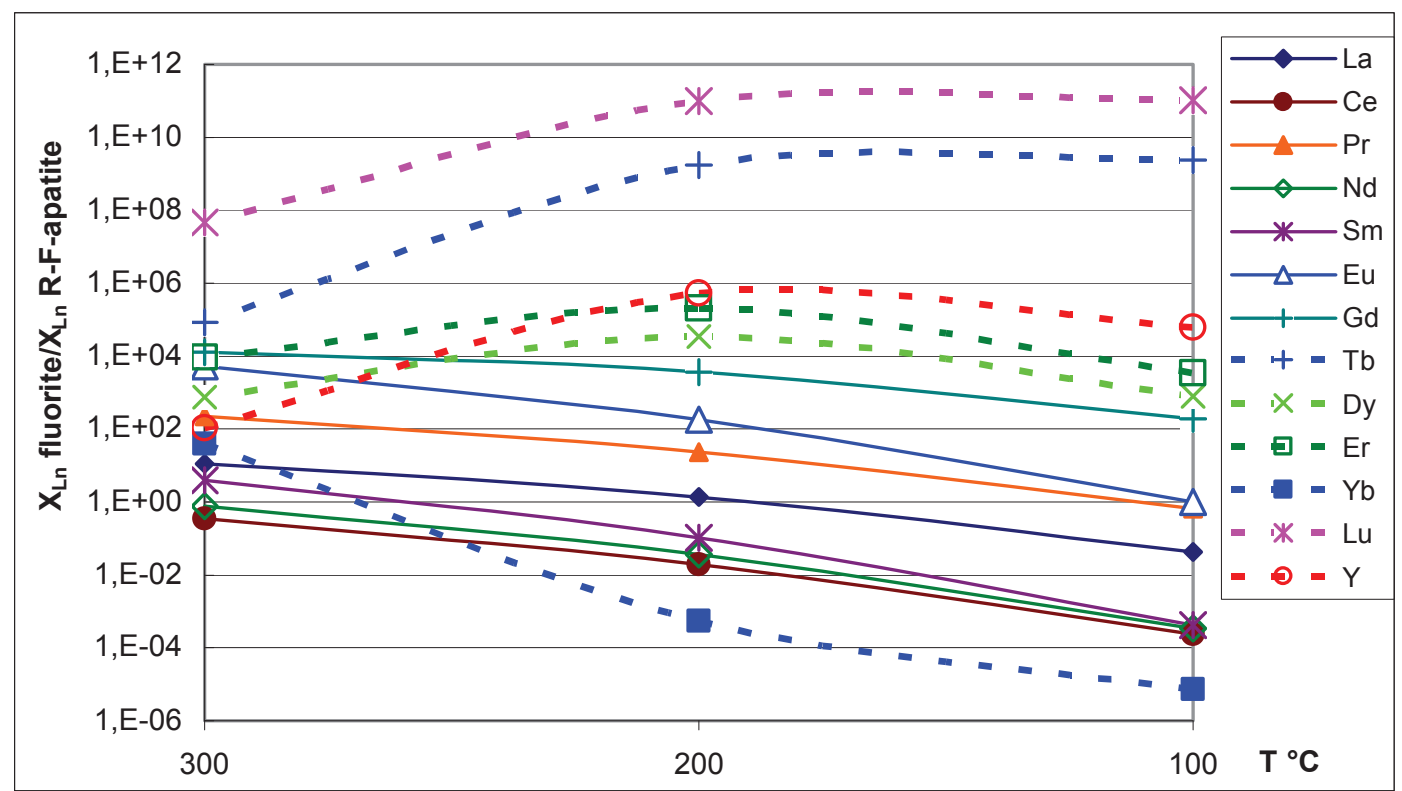

Рис. 3. Мольные коэффициенты распределения РЗЭ между флюоритом и фторапатитом в зависимости от температуры (и других сопряженных с ней параметров (рис. 1))

Fig. 3. Molar coefficients of REE distribution between fluorite and fluorapatite as a function of temperature (and other parameters associated with it (Fig. 1)) 


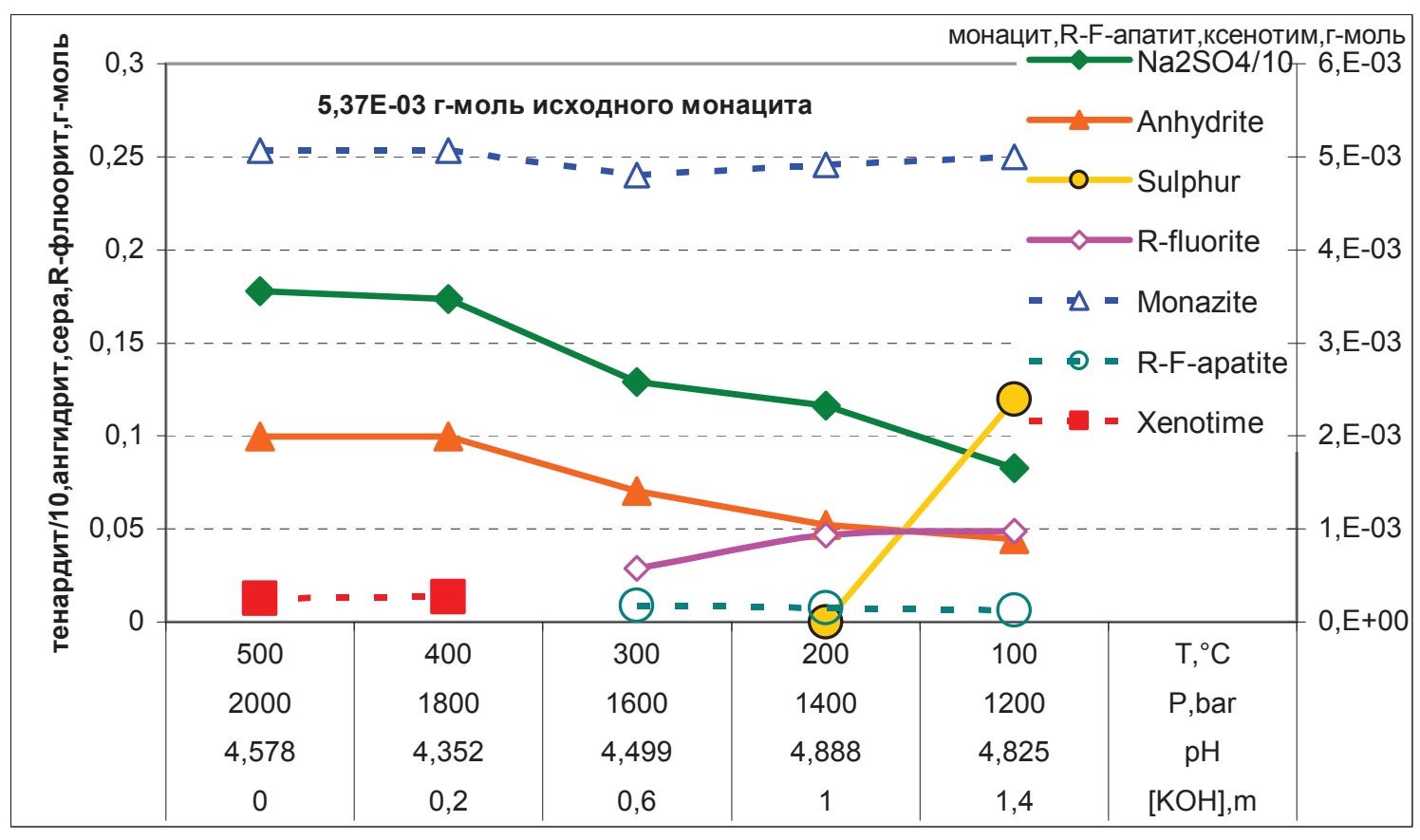

Рис. 4. Соотношение равновесных твердых фаз в зависимости от параметров слабокислого рудообразующего флюида: [0,1 г-моль $\mathrm{CaCO}_{3}+0,0053$ г-моль монацита $]_{\text {тв }}+1 \mathrm{~m} \mathrm{NaCl}+5 \mathrm{~m} \mathrm{NaHCO}_{3}+2 \mathrm{~m} \mathrm{NaHSO}_{4}+0,1 \mathrm{~m} \mathrm{HF+0,1} \mathrm{m} \mathrm{H}_{2} \mathrm{~S}+3,8 \mathrm{~m} \mathrm{HCl}+$ $0,4(i-0,5) \mathrm{m} \mathrm{KOH}+1 \mathrm{Kr} \mathrm{H}_{2} \mathrm{O}$

Fig. 4. Relationship of equilibrium solid phase as a function of the parameters of a weakly acidic ore-forming fluid: $\left[0,1\right.$ mole $\mathrm{CaCO}_{3}+$ $0,0053$ mole monazite $]_{\text {solid }}+1 \mathrm{~m} \mathrm{NaCl}^{2} \mathrm{~m} \mathrm{NaHCO}_{3}+2 \mathrm{~m} \mathrm{NaHSO}_{4}+0,1 \mathrm{~m} \mathrm{HF}^{2} 0,1 \mathrm{~m} \mathrm{H}_{2} \mathrm{~S}+3,8 \mathrm{~m} \mathrm{HCl}+0,4(i-0,5) \mathrm{m} \mathrm{KOH}+$ $1 \mathrm{~kg} \mathrm{H} \mathrm{H}_{2} \mathrm{O}$

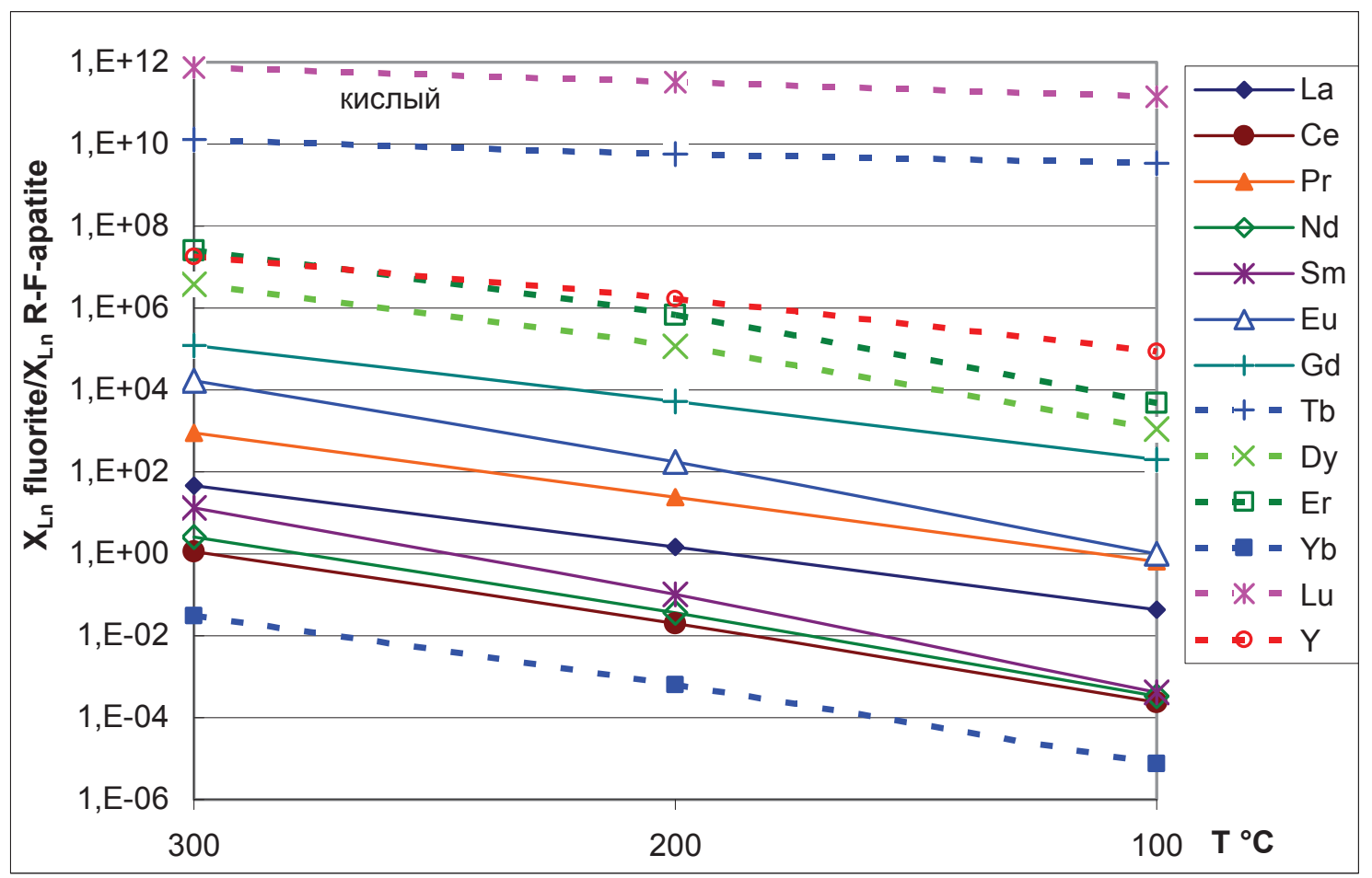

Рис. 5. Мольные коэффициенты распределения РЗЭ между флюоритом и фторапатитом при слабокислом флюиде в зависимости от температуры (и сопряженных с ней параметров (рис. 4))

Fig. 5. Mole coefficients of REE distribution between fluorite and fluorapatite in weakly acidic fluids as a function of temperature (and the parameters associated with it (Fig. 4)) 
РЗЭ между монацитом и РЗЭ-фторапатитом почти совпадают с таковыми в интервале $300-100{ }^{\circ} \mathrm{C}$ в слабощелочном варианте (рис. 2), т. е. легкие РЗЭ вплоть до гадолиния предпочитают вхождение в монацит, а не в РЗЭ-фторапатит. Близкая картина в слабокислом варианте в сравнении со слабощелочным наблюдается для коэффициентов распределения РЗЭ между монацитом и РЗЭ-флюоритом. Небольшая разница заключается в том, что при слабокислом флюиде кривые зависимости коэффициентов от температуры менее вогнуты, т. к. при 200-100 ${ }^{\circ} \mathrm{C}$ коэффициенты имеют практически те же значения, что и при слабощелочном флюиде, но при $300{ }^{\circ} \mathrm{C}$ они примерно на половину порядка ниже, хотя ряд последовательности сохраняется: $\mathrm{Gd}<\mathrm{La}<\operatorname{Pr}<\mathrm{Ce}<\mathrm{Nd}<\mathrm{Eu}<\mathrm{Sm}$.

Распределение РЗЭ между флюоритом и фторапатитом в слабокислых условиях (рис. 5) заметно отличается от варианта со слабощелочным флюидом (рис. 3). Кривые зависимости величин коэффициентов распределения от температуры во всем интервале сосуществования минералов практически представляют собой прямые линии с понижением от 300 к $100{ }^{\circ} \mathrm{C} . \mathrm{Kd}_{\mathrm{x}}<1$ во всем интервале наблюдаются для $\mathrm{Yb}$ и Се, при 200-100 ${ }^{\circ} \mathrm{C}$ для неодима и самария, при $100{ }^{\circ} \mathrm{C}$ для лантана, празеодима и европия, т. е. в перечисленных условиях эти РЗЭ обогащают фторапатит. Во всех остальных случаях коэффициенты выше единицы, т. е. здесь РЗЭ предпочтительнее уходят во флюорит. В целом наблюдается следующий порядок возрастания величин $\mathrm{Kd}$ : $\mathrm{Yb}<\mathrm{Ce}<\mathrm{Nd}<\mathrm{Sm}<\mathrm{La}<\operatorname{Pr}<\operatorname{Eu}<\mathrm{Gd}<\mathrm{Dy}<\mathrm{Er}<\mathrm{Y}<<\mathrm{Tb}<\mathrm{Lu}$.

Таким образом, кислотность-щелочность флюидов заметно сказывается только на распределении РЗЭ между флюоритом и фторапатитом. Основное же влияние на фракционирование РЗЭ оказывает температура. При этом только для пары монацит/РЗЭ-флюорит понижение температуры способствует росту величин коэффициентов распределения, т. е. вхождению РЗЭ в монацит. В парах монацит/РЗЭ-фторапатит, ксенотим/РЗЭ-фторапатит и в кислых условиях в паре РЗЭ-флюорит/РЗЭ-фторапатит понижение температуры сопровождается уменьшением величин коэффициентов распределения и способствует некоторому обогащению фторапатита редкими землями. В слабощелочном варианте для пары РЗЭ-флюорит/РЗЭфторапатит зависимость от температуры распределения редких земель гораздо более сложная и разная для легких и тяжелых РЗЭ (рис. 3). Для легких РЗЭ вплоть до среднего - гадолиния - понижение температуры вызывает и уменьшение величин коэффициентов распределения в паре РЗЭ-флюорит/РЗЭ-фторапатит вплоть до значений меньше единицы, особенно для церия, неодима и частично самария, т. е. РЗЭ-фторапатит по сравнению с РЗЭ-флюоритом обогащается этими элементами, тогда как тяжелые РЗЭ легче входят в РЗЭ-флюорит. Выводы, полученные расчетным путем, подтверждаются природными данными: обогащение легкими РЗЭ фторапатита из карбонатитов редко- метального месторождения Миаоя (Miaoya, Центральный Китай) отмечается в работе [20].

Для слабощелочного варианта (рис. 1) помимо $\mathrm{Kd}_{\mathrm{x}}$ были рассчитаны коэффициенты распределения РЗЭ от лантана до гадолиния между монацитом и РЗЭ-флюоритом (рис. 6, слева) и всего ряда лантаноидов между РЗЭ-флюоритом и РЗЭ-фторапатитом (рис. 6, справа) в интервале их сосуществования $\left(300-100^{\circ} \mathrm{C}\right)$ не как отношение мольных долей каждого лантаноида, а как отношение их содержаний в этих минералах, пересчитанное на мг/т (т. е. в ppm). Несмотря на изменение численных величин коэффициентов, выраженных разными способами $\left(\mathrm{Kd}_{\mathrm{ppm}}\right.$ монацит/РЗЭ-флюорит примерно на половину порядка ниже $\mathrm{Kd}_{\mathrm{x}}$ в этой паре), характер зависимости $\mathrm{Kd}_{\mathrm{ppm}}$ от параметров охлаждающегося флюида остается абсолютно идентичным зависимости $\mathrm{Kd}_{\mathrm{x}}$. Аналогичная картина получена для пары РЗЭ-флюорит/РЗЭ фторапатит: характер зависимости от параметров охлаждающегося флюида, так же как и для пары минералов монацит и РЗЭ-флюорит, остается идентичным зависимости $\mathrm{Kd}_{\mathrm{x}}$, но численные значения $\mathrm{Kd}_{\mathrm{ppm}}$ примерно на порядок выше, чем $\mathrm{Kd}_{\mathrm{x}}$.

\section{Коэффициенты распределения Р3Э+Ү между \\ РЗЭ-содержащими минералами \\ и слабощелочным флюидом}

Распределение РЗЭ+Ү между минералами и флюидом в нашем случае оценивалось с помощью массовых коэффициентов, где масса элемента выражена в г/т (т. е. - ppm) $\mathrm{Kd}_{\text {ppm }}$ (далее $\mathrm{Kd}$ ). На рис. 7 приведены составы исходного флюида (при условии, что весь монацит растворится в 1 кг $\mathrm{H}_{2} \mathrm{O}$ ) и концентрации РЗЭ+Ү во флюидах, равновесных с РЗЭ-содержащими минералами при соответствующих температурах. Как видно из рис. 7, с понижением температуры концентрация РЗЭ+Y в равновесном флюиде уменьшается, за исключением Yb при $200{ }^{\circ} \mathrm{C}$. При температурах $500-300{ }^{\circ} \mathrm{C}$ в равновесных флюидах наблюдается однотипный плавный характер спектров РЗЭ+Y с четко выраженным тетрад эффектом. Исключением является наличие европиевого максимума при $500{ }^{\circ} \mathrm{C}$, отсутствующего при 400 и $300{ }^{\circ} \mathrm{C}$. Такой вид спектров, очевидно, обусловлен одинаковой ассоциацией устойчивых РЗЭ-содержащих фаз: монацит - концентратор легких РЗЭ (ЛРЗЭРО 4$),+$ ксенотим - тяжелых $\left(\mathrm{TP} Э Р О_{4}\right),+$ РЗЭ-фторапатит.

При 200 и $100{ }^{\circ} \mathrm{C}$ характер спектров РЗЭ резко меняется, т. к. из равновесной ассоциации исчезает ксенотим и появляется РЗЭ-рлюорит. Исчезновение ксенотима приводит к обогащению равновесного флюида тяжелыми РЗЭ (ТРЗЭ), особенно резко возрастает концентрация $\mathrm{Yb}$, т. к. если прочие ТРЗЭ частично поглощаются преимущественно РЗЭ-флюоритом, то иттербий, имеющий самое высокое значение свободной энергии среди прочих $\mathrm{LnF}_{3}$, практически не входит в РЗЭ-флюорит. Это хорошо видно по величинам $\mathrm{Kd}$ РЗЭ-флюорит/флюид, где Yb имеет самые низкие величины 


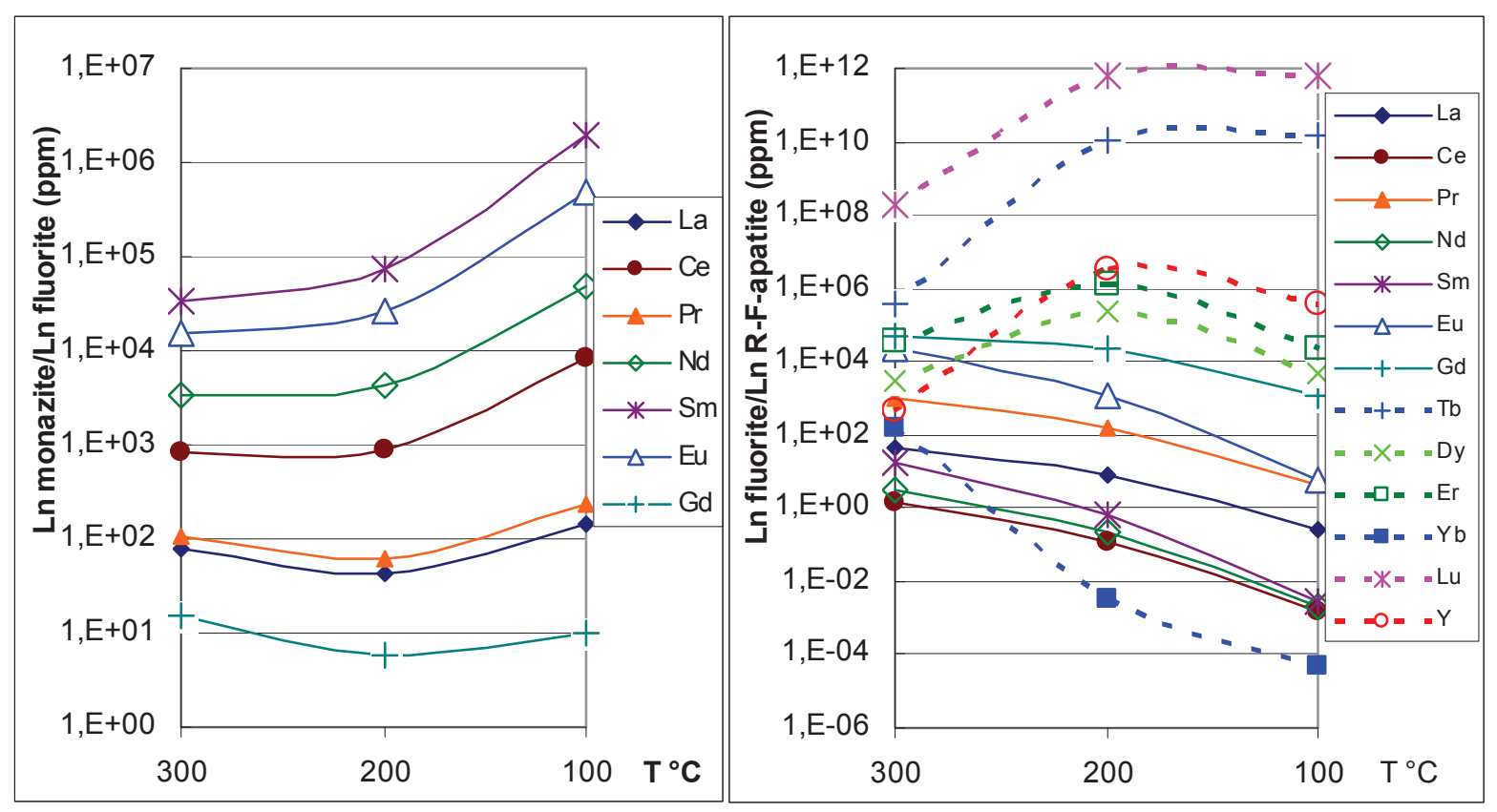

Рис. 6. Коэффициенты распределения РЗЭ монацит/РЗЭ-флюорит и РЗЭ-флюорит/РЗЭ-фторапатит в зависимости от температуры (и сопряженных с ней параметров (рис. 1)), где $K d=L n_{\text {монаит }} / L n_{\text {флюорит }}(p p m)$

Fig. 6. Coefficients of REE distribution in monazite/REE-fluorite and REE-fluorite/REE-fluorapatite depending on temperature (and the parameters associated with it (Fig. 1)), where $K d=L n_{\text {monazite }} L n_{\text {fluorite }}(p p m)$

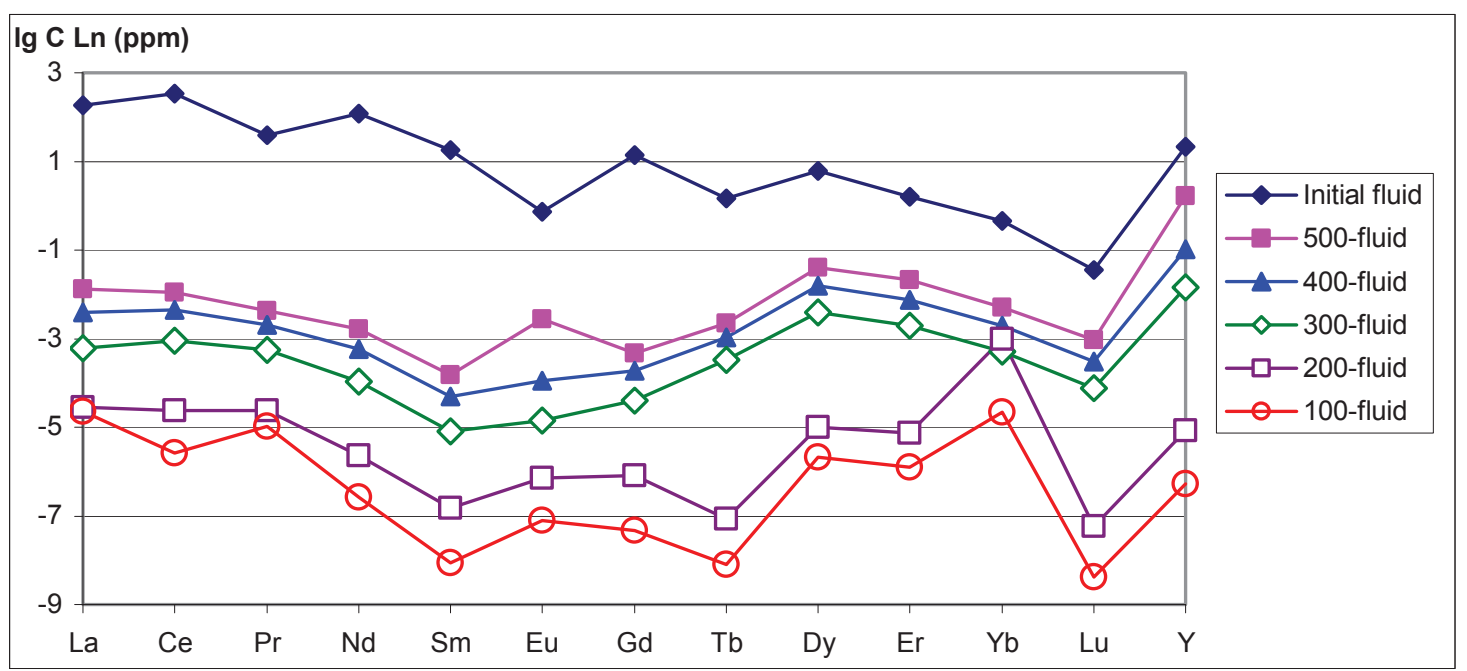

Рис. 7. Сравнение концентраций РЗЭ+Ү в исходном флюиде и во флюидах, равновесных с РЗЭ-содержащими минералами (монацитом, ксенотимом, РЗЭ-флюоритом и РЗЭ-фторапатитом)

Fig. 7. Comparison of REE $+Y$ concentrations in the initial fluid and in fluids equilibrium with REE-bearing minerals (monazite, xenotime, REE-fluorite and REE-fluorapatite)

коэффициентов распределения. Наиболее высокие значения коэффициентов распределения показывают тяжелые РЗЭ. Так, при $100{ }^{\circ} \mathrm{C}$ выстраивается следующий ряд значений $\mathrm{Kd}$ флюорит/флюид: $\mathrm{Tb}>\mathrm{Gd} \geq \mathrm{Y}>\mathrm{Lu}>\mathrm{Dy}>\mathrm{Er}>>\mathrm{La}>\mathrm{Pr}=\mathrm{Ce}>\mathrm{Nd}>>\mathrm{Sm}>>\mathrm{Eu}$ $\geq \mathrm{Yb}$. При этом присутствие ксенотима при $300{ }^{\circ} \mathrm{C}$ вызывает понижение коэффициентов распределения в наибольшей степени именно для ТРЗЭ+Ү (на 2 порядка и более), тогда как коэффициенты распределения легких РЗЭ меняются не так значительно.
Наиболее сложные зависимости коэффициентов распределения РЗЭ обнаруживаются для пары фторапатит/флюид (рис. 8). В интервале температур 500-300 ${ }^{\circ} \mathrm{C}$ наблюдается почти прямолинейный их рост при охлаждении флюида, который сохраняется и далее для легких и средних РЗЭ. Для тяжелых РЗЭ и иттрия в интервале температур $300-100{ }^{\circ} \mathrm{C}$ кривые зависимости Kd от температуры имеют вогнутый характер с минимумом при $200{ }^{\circ} \mathrm{C}$, причем от $200 \mathrm{\kappa} 100{ }^{\circ} \mathrm{C}$ наблюдается рост коэффициентов распределения в ряду $\mathrm{Yb}>>\mathrm{Dy}>\mathrm{Y} \geq \mathrm{Er}>>\mathrm{Tb}>>\mathrm{Lu}$. Сле- 


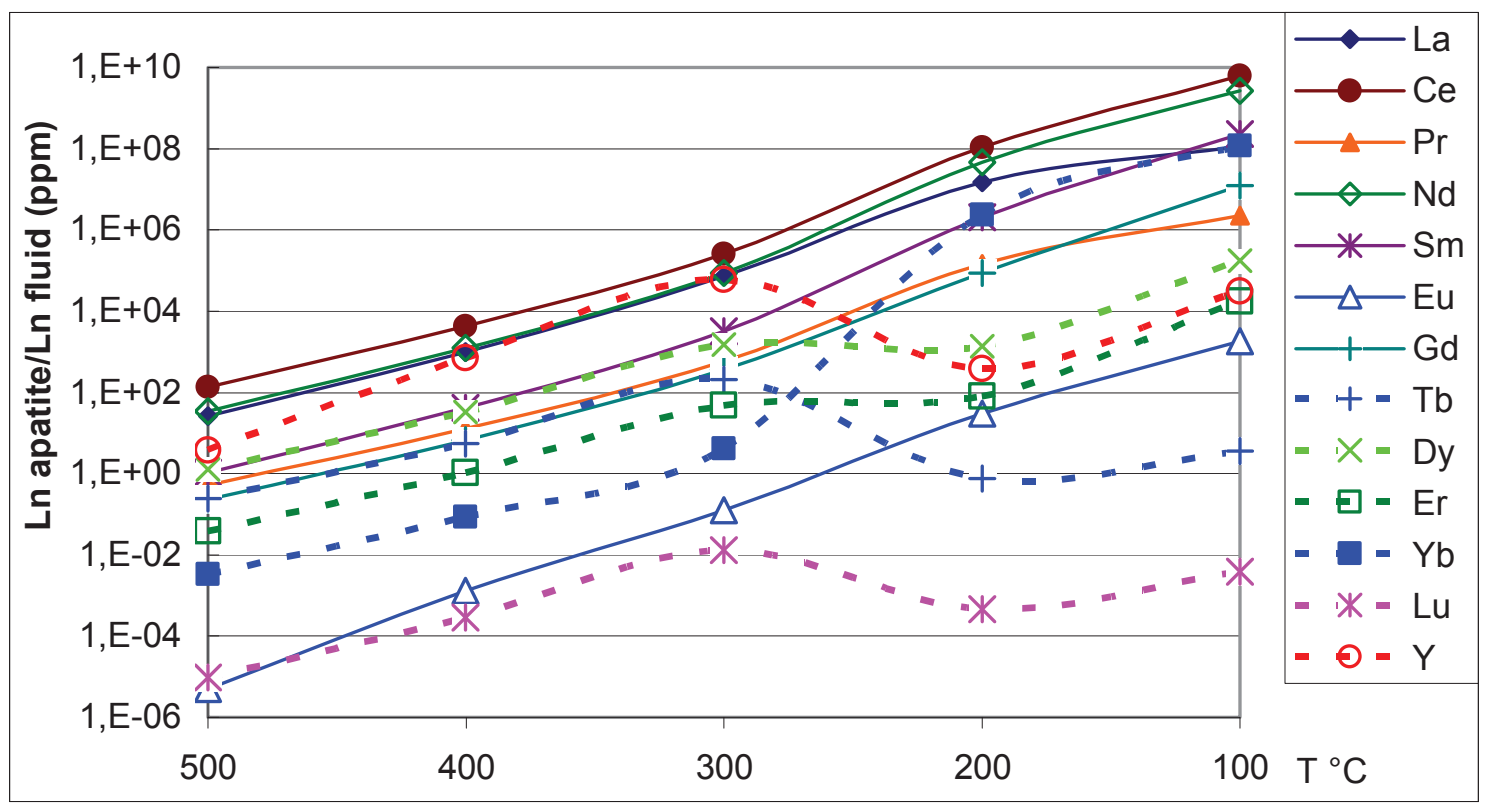

Рис. 8. Коэффициенты распределения РЗЭ+Ү между фторапатитом и равновесным флюидом в зависимости от параметров системы

Fig. 8. Coefficients of $R E E+Y$ distribution between fluorapatite and the equilibrium fluid, depending on the parameters of the system

дует заметить, что кривая иттербия вновь стоит особняком: она имеет выпуклый характер с резким (на 6 порядков) возрастанием от 300 к $200{ }^{\circ} \mathrm{C}$ и умеренным (на 2 порядка) ростом к $100{ }^{\circ} \mathrm{C}$. Такое поведение ТРЗЭ и иттрия обусловлено сменой твердофазовой равновесной ассоциации: появлением РЗЭ-флюорита начиная с $300{ }^{\circ} \mathrm{C}$ и исчезновением ксенотима при 200 и $100{ }^{\circ} \mathrm{C}$. При этом для $\mathrm{Kd}$ фторапатит/флюид тяжелых РЗЭ и иттрия наблю- дается сложная картина: при $500{ }^{\circ} \mathrm{C} \mathrm{Kd}<1$ : от $9,43 \mathrm{E}-6$ - Lu до 0,25 - Tb, причем для лютеция $\mathrm{Kd}<1$ остается во всем интервале температур (500-100 ㄷ). Для тяжелых в целом выстраивается ряд $\mathrm{Kd}: \mathrm{Lu}<\mathrm{Yb}<\mathrm{Er}<\mathrm{Tb}<\mathrm{Dy}<\mathrm{Y}$, поэтому $\mathrm{Kd}<1$ для иттербия только при 500 и $400{ }^{\circ} \mathrm{C}$, а для эрбия и тербия только при $500{ }^{\circ} \mathrm{C}$, при этом к ним присоединяется еще и гадолиний с празеодимом. Для Dy и $\mathrm{Y} \mathrm{Kd}>1$ уже и при $500{ }^{\circ} \mathrm{C}$. Все это свидетельству-

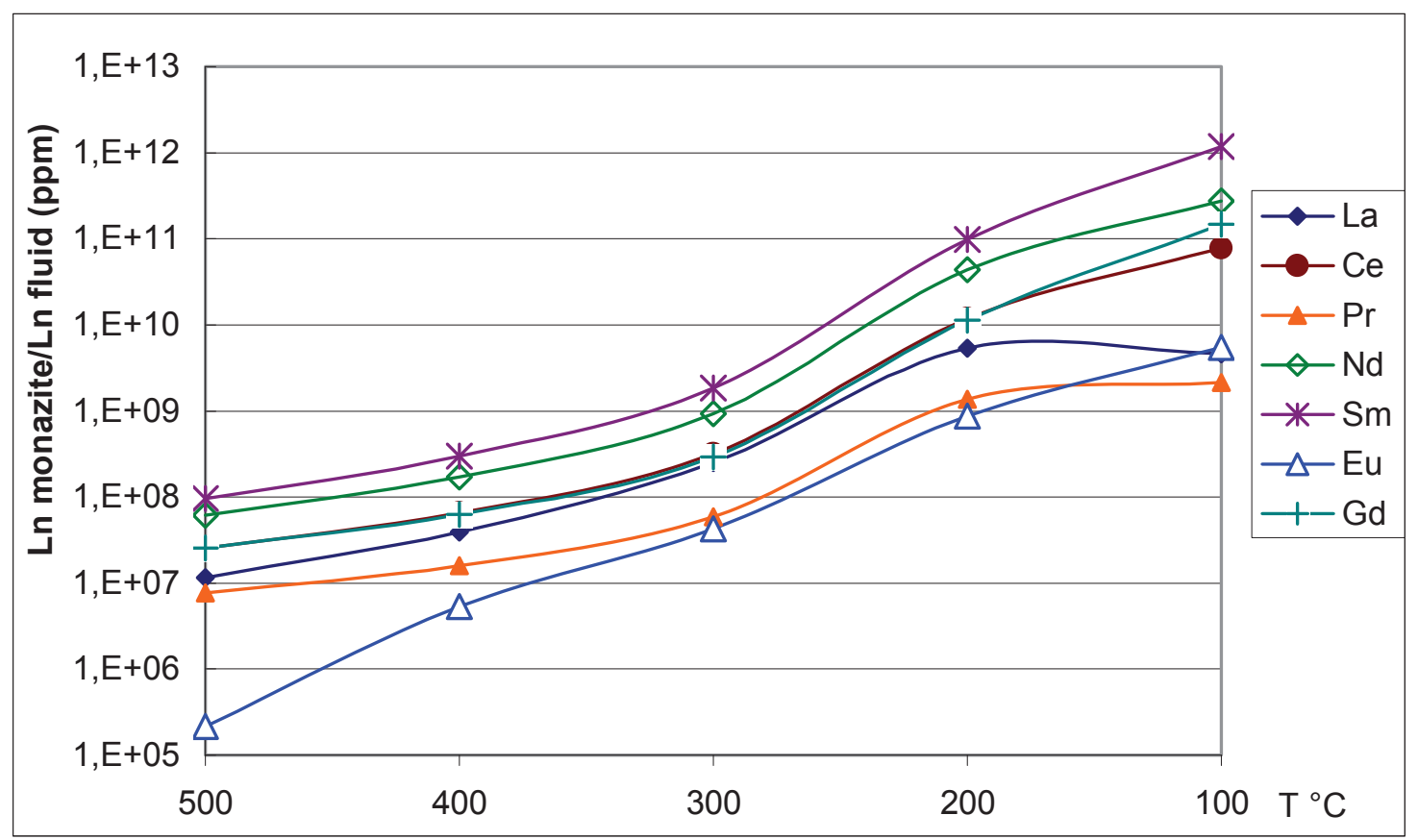

Рис. 9. Коэффициенты распределения РЗЭ монацит/флюид в зависимости от параметров системы

Fig. 9. Distribution coefficients of REE monazite/fluid depending on the parameters of the system 
ет о том, что РЗЭ-фторапатит не является концентратором тяжелых лантаноидов, преимущественно отдавая их во флюид, в отличие от легких РЗЭ, для которых Kd выстраиваются в следующий ряд: $\mathrm{Ce}>\mathrm{Nd} \geq \mathrm{La}>\mathrm{Sm}>\mathrm{Pr}$.

Для коэффициентов распределения ТРЗЭ+Y между ксенотимом (устойчивым в интервале 500-300 ${ }^{\circ} \mathrm{C}$ ) и охлаждающимся флюидом из общей картины монотонного возрастания $\mathrm{Kd}$ в ряду $\mathrm{Lu}<\mathrm{Er}<\mathrm{Yb}<\mathrm{Dy}<\mathrm{Tb}$ при охлаждении флюида выделяется Ү. Ввиду высокой его концентрации во флюиде при $500{ }^{\circ} \mathrm{C}$ (благодаря повышенной устойчивости здесь фторокомплекса $\mathrm{YF}_{2}^{+}$) $\mathrm{Kd}$ $\mathrm{YPO}_{4} /$ флюид оказывается самым низким и только с падением температуры резко возрастающим на два с лишним порядка при $300{ }^{\circ} \mathrm{C}$, так что его кривая сечет кривые $\mathrm{Kd} \mathrm{Lu,} \mathrm{Er} \mathrm{и} \mathrm{Yb}$, а при $300{ }^{\circ} \mathrm{C}$ достигает значения $\mathrm{Kd} \mathrm{DyPO} /$ /флюид.

Для пары монацит/флюид (рис. 9) наблюдается монотонный рост коэффициентов распределения при охлаждении флюида, что обусловлено равномерным понижением концентрации легких и средних лантаноидов (от La до Gd) во флюиде с понижением его температуры (от $2,16 \mathrm{E}+5$ для $\mathrm{Eu}$ до $9,69 \mathrm{E}+7$ для $\mathrm{Sm}$ при $500{ }^{\circ} \mathrm{C}$; от $2,14 \mathrm{E}+9$ для $\operatorname{Pr}(\mathrm{Kd}$ $\mathrm{Pr}<\mathrm{Kd} \mathrm{Eu}$ при $\left.100{ }^{\circ} \mathrm{C}\right)$ до $1,18 \mathrm{E}+12$ для $\mathrm{Sm}$ при $\left.100{ }^{\circ} \mathrm{C}\right)$. В целом порядок $\mathrm{Kd} \mathrm{LnPO}_{4} /$ флюид следующий: $\mathrm{Sm}>\mathrm{Nd}>\mathrm{Gd}=\mathrm{Ce}>\mathrm{La}>\mathrm{Pr}>\mathrm{Eu}$ (за исключением $100{ }^{\circ} \mathrm{C}$ для последних Ln).

Таким образом, в парах минерал/равновесный флюид коэффициенты распределения в слабощелочном флюиде в основном возрастают с падением температуры, хотя для пары РЗЭ-флюорит/флюид при $100{ }^{\circ} \mathrm{C}$ наблюдается некоторое понижение $\mathrm{Kd}$ для легких и средних лантаноидов. Тем не менее в подавляющем большинстве случаев (т. е. для монацита, ксенотима и РЗЭ-флюорита) Kd минерал/флюид выше единицы, и это означает, что при охлаждении равновесного флюида РЗЭ+Y преимущественно концентрируются в этих минералах. Исключение составляет Kd фторапатит/флюид, где для тяжелых РЗЭ и иттрия наблюдается сложная картина: при $500{ }^{\circ} \mathrm{C} \mathrm{Kd}<1$ : от $9,43 \mathrm{E}-6$ - Lu до 0,25 $\mathrm{Tb}$, при этом для лютеция $\mathrm{Kd}<1$ остается во всем интервале температур $\left(500-100{ }^{\circ} \mathrm{C}\right)$, а также для европия в интервале $500-300{ }^{\circ} \mathrm{C}$. Для тяжелых в целом выстраивается ряд $\mathrm{Kd}: \mathrm{Lu}<\mathrm{Yb}<\mathrm{Er}<\mathrm{Tb}<\mathrm{Dy}<\mathrm{Y}$, поэтому $\mathrm{Kd}<1$ для иттербия только при 500 и $400{ }^{\circ} \mathrm{C}$, а для эрбия и тербия только при $500{ }^{\circ} \mathrm{C}$, при этом к ним присоединяется еще и гадолиний с празеодимом. Для Dу и Y Kd>1 уже и при $500{ }^{\circ} \mathrm{C}$. Bce это свидетельствует о том, что РЗЭ-фторапатит не является концентратором тяжелых РЗЭ+Y, преимущественно отдавая их во флюид, в отличие от

\section{СПИСОК ЛИТЕРАТУРЫ}

1. REE fractionation, mineral speciation, and supergene enrichment of the Bear Lodge carbonatites, Wyoming / A.K. Andersen, J.G. Clark, P.B. Larson, J.J. Donovan // Ore Geology Reviews. -2017 . - V. 89. - P. 780-807. легких лантаноидов, для которых Kd выстраиваются в следующий ряд: $\mathrm{Ce}>\mathrm{Nd} \geq \mathrm{La}>\mathrm{Sm}>\mathrm{Pr}$.

\section{Заключение}

Изучение коэффициентов распределения РЗЭ+Ү между минералами-концентраторами этих элементов и между минералами и сульфатными флюидами в различных щелочных и слабокислых системах позволяют получить недостающие параметры, необходимые для моделирования процессов кристаллизации и рудогенеза в пределах карбонатитовых рудно-магматических систем. На основании изучения редкоземельного состава минералов карбонатитов [21-23] был сделан важный вывод о роли процесса фракционной кристаллизации карбонатитового расплава на распределение РЗЭ. Высокотемпературные экспериментальные исследования карбонатитовых систем показывают, что РЗЭ накапливаются в гидротермальном растворе и кристаллизуются в виде собственных минеральных фаз благодаря их перераспределению флюидами в РЗЭ-содержащих магматических минеральных фазах, например апатит [24, 25]. Флюиды, участвующие в переносе и кристаллизации РЗЭ-минералов, имеют высокую активность анионных лигандов $\left(\mathrm{F}, \mathrm{Cl}, \mathrm{CO}_{2}\right.$, $\mathrm{SO}_{4}$ ) [26-29], что подтверждается исследованиями флюидных и расплавных включений в минералах [30-32]. В отличие от выше цитированных работ, посвященных в основном рассмотрению коэффициентов распределения РЗЭ минерал/расплав или минерал/флюид при высоких Т-Р параметрах, в настоящей работе коэффициенты распределения РЗЭ+Y рассматриваются для условий, типичных для гидротермальных процессов. Показано, что коэффициенты распределения РЗЭ+Y между минералами большей частью не зависят от кислотно-щелочной обстановки минералообразования. Основное влияние на фракционирование РЗЭ оказывает температура и сопряженные с нею параметры. Только для пары монацит/РЗЭ-флюорит понижение температуры способствует росту величин коэффициентов распределения, т. е. вхождению РЗЭ в монацит. В парах монацит/РЗЭ-фторапатит, ксенотим/РЗЭфторапатит и в кислых условиях в паре РЗЭ-флюорит/РЗЭ-фторапатит понижение температуры сопровождается уменьшением величин коэффициентов распределения и способствует обогащению фторапатита редкими землями. Для монацита, ксенотима и РЗЭ-флюорита $\mathrm{Kd}$ минерал/флюид выше единицы, и это означает, что при охлаждении равновесного флюида РЗЭ+Y преимущественно концентрируются в этих минералах.

Исследование выполнено за счет средств и по теле проекта НИР ИГМ СО РАН № 0330-2016-0002.

2. Ce (III) and Ce (IV) (re) distribution and fractionation in a laterite profile from Madagascar: Insights from in situ XANES spectroscopy at the Ce LIII-edge / E. Janots, F. Bernier, F. Brunet, M. Munoz, N. Trcera, A. Berger, M. Lanson // Geochim. et cosmochim. acta. - 2015. - V. 153. - P. 134-148. 
3. Smythe D.J., Brenan J.M. Cerium oxidation state in silicate melts: Combined $\mathrm{fO}_{2}$, temperature and compositional effects // Geochim. et cosmochim. acta. - 2015. - V. 170. - P. 173-187.

4. Experimental studies of REE fractionation during water-mineral interactions: REE release rates during apatite dissolution from pH 2.8 to 9.2 / S.J. Kohler, N. Harouiya, C. Chairat, E.H. Oelkers // Chemical Geology. - 2005. - V. 222. - P. 168-182.

5. Li H., Hermann J. The effect of fluorine and chlorine on trace element partitioning between apatite and sediment melt at subduction zone conditions // Chemical Geology. - 2017. - V. 473. P. $55-73$.

6. Liang Y., Liu B. Simple Models for Disequilibrium Fractional Melting and Batch Melting with Application REE fractionation in abyssal peridotites // Geochim. et cosmochim. acta. - 2016. V. 173. - P. 181-197.

7. Wohlers A., Wood B.J. Uranium, thorium and REE partitioning into sulfide liquids: Implications for reduced S-rich bodies // Geochim. et cosmochim. acta. - 2017. - V. 205. - P. 226-244.

8. Toyama K., Terakado Y. Experimental study of rare earth element partitioning between calcite and sodium chloride solution at room temperature and pressure // Geochem. J. -2014. - V. 48. P. 463-477.

9. Curti E., Kulik D.A., Tits J. Solid solutions of trace Eu (III) in calcite: Thermodynamic evaluation of experimental data over a wide range of $\mathrm{pH}$ and $\mathrm{pCO}_{2} / /$ Geochim. et cosmochim. acta. - 2005. V. 69. - P. 1721-1737.

10. Lakshtanov L.Z., Stipp S.L.S. Experimental study of europium (III) coprecipitation with calcite // Geochim. et cosmochim. acta. - 2004. - V. 68. - P. 819-827.

11. Karato S. Physical basis of trace element partitioning: a review // American Mineralogist. - 2016. - V. 101. - P. 2577-2593.

12. REE distribution between ferrous mica, $\mathrm{K}$-feldspar and kalsilite at $500{ }^{\circ} \mathrm{C}$ and $1 \mathrm{~kb}$ in $\mathrm{KOH}$ solution / L.F. Suvorova, E.V. Kaneva, S.V. Lipko, V.L. Tauson, V.K. Taroev, A.A. Kashaev // Experiment in Geosciences. - 2017. - V. 23. - № 1. - P. 104-107.

13. Amphibole-melt trace element partitioning of fractionating calcalkaline magmas in the lower crust: an experimental study / R.H. Nandedkar, N. Hurlimann, P. Ulmer, 0. Muntener // Contrib Mineral Petrol. - 2016. - V. 171:71.

14. Zajacz Z. The effect of melt composition on the partitioning of oxidized sulfur between silicate melts and magmatic volatiles // Geochim. et cosmochim. acta. - 2015. - V. 158. -P. 223-244.

15. Широносова Г.П., Колонин Г.Р. Термодинамическое моделирование распределения РЗЭ между монацитом, флюоритом и апатитом // ДАН. - 2013. - Т. 450. - № 4. - С. 455-459.

16. Voigt M., Mavromatis V., Oelkers E.H. The experimental determination of REE partition coefficients in the water-calcite system // Chemical Geology. - 2017. - V. 462. - P. 30-43.

17. Широносова Г.П., Прокопьев И.Р. Поведение РЗЭ+Ү во фторидно-хлоридно-сульфидно-сульфатно-карбонатных средах на гидротермальных стадиях щелочных магматических комплексов по данным термодинамического моделирования // Известия ТПУ. Инжиниринг георесурсов. - 2017. - Т. 328. № $12 .-$ C. $75-83$.

18. Шваров Ю.В. НCh: новые возможности термодинамического моделирования геохимических процессов, предоставляемые Windows // Геохимия. - 2008. - № 8. - С. 898-903.

19. Shvarov Yu.V., Bastrakov E. HCh: a Software Package for Geochemical Equilibrium Modeling: User's Guide (AGSO RECORD, 1999). - Canberra: Dept. Industry, Australian Geol. Surv. Org., Sci. Resour., 1999. -57 p.
20. A case example of the importance of multi-analytical approach in deciphering carbonatite petrogenesis in South Qinling orogen: Miaoya rare-metal deposit, central China / Ch. Xu, J. Kynicky, A.R. Chakhmouradian, X. Li, W. Song // Lithos. - 2015. V. 227. - P. 107-121.

21. Trace element modeling of the magmatic evolution of rare-earthrich carbonatite from the Miaoya deposit, Central China / Ch. Xu, J. Kynicky, A.R. Chakhmouradian, I.H. Campbell, Ch.M. Allen // Lithos. - 2010. - V. 118. - P. 145-155.

22. Rare earth elements in phoscorites and carbonatites of the Devonian Kola Alkaline Province, Russia: examples from Kovdor, Khibina, Vuoriyarvi and Turiy Mys complexes / A.N. Zaitzev, T. Willaims, T. Jeffries, S. Strekopytov, J. Moutte, O.V. Ivashchenkova, J. Spratt, S.V. Petrov, F. Wall, R. Seltmann, A.P. Borozdin // Ore Geology Reviews. - 2014. - V. 61. - P. 204-225.

23. Trace-element composition of minerals and rocks in the Belaya Zima carbonatite complex (Russia): Implications for the mechanisms of magma evolution and carbonatite formation / A.G. Doroshkevich, I.V. Veksler, R. Klemd, E.A. Khromova, I.A. Izbrodin / Lithos. -2010. - V. 284-285. - P. 91-108.

24. Harlov D.E., Wirth R., Förster H.-J. An experimental study of dissolution-reprecipitation in fluorapatite: fluid infiltration and the formation of monazite // Contributions to Mineralogy and Petrology. - 2005. - V. 150. - P. 268-286.

25. Harlov D.E., Förster H-J. Fluid induced nucleation of (Y+REE)phosphate minerals within apatite: Nature and experiment Part II. Fluorapatite // American Mineralogist. -2003. - V. 88. P. 1209-1229.

26. Williams-Jones A.E., Migdisov A.A., Samson I.M. Hydrothermal Mobilisation of the Rare Earth Elements - a Tale of «Ceria» and "Yttria» // Elements. - 2012. - V. 8 (5). - P. 355-360.

27. Tropper P., Manning C.E., Harlov D.E. Solubility of $\mathrm{CePO}_{4}$ monazite and $\mathrm{YPO}_{4}$ xenotime in $\mathrm{H}_{2} \mathrm{O}$ and $\mathrm{H}_{2} \mathrm{O}-\mathrm{NaCl}$ at $800{ }^{\circ} \mathrm{C}$ and $1 \mathrm{GPa}$ : Implications for REE and Y transport during high-grade metamorphism // Chemical Geology. - 2011. - V. 282. P. 58-66.

28. Tropper P., Manning C.E., Harlov D.E. Experimental determination of $\mathrm{CePO}_{4}$ and $\mathrm{YPO}_{4}$ solubilities in $\mathrm{H}_{2} \mathrm{O}-\mathrm{NaF}$ at $800{ }^{\circ} \mathrm{C}$ and $1 \mathrm{GPa}$ : Implications for rare earth element transport in high-grade metamorphic fluids // GeoFluids. - 2013. - V. 13. P. $372-380$.

29. Термодинамическое моделирование поведения РЗЭ в высококонцентрированных по сульфатной сере окисленных гидротермальных флюидах / Г.П. Широносова, Г.Р. Колонин, А.А. Боровиков, А.С. Борисенко // ДАН. - 2016. - Т. 469. № 5. - C. 611-615.

30. The nature of orthomagmatic, carbonatitic fluids precipitating $\mathrm{REE}, \mathrm{Sr}$-rich fluorite: fluid-inclusion evidence from the Okorusu fluorite deposit, Namibia / B. Buhn, A.H. Rankin, J. Schneider, P. Dulski // Chemical geology. - 2002. - V. 186. - P. 75-98.

31. Origin of REE-rich ferrocarbonatites in southern Siberia (Russia): implications based on melt and fluid inclusions / I.R. Prokopyev, A.S. Borisenko, A.A. Borovikov, G.G. Pavlova // Mineralogy and Petrology. - 2016. - V. 110. - P. 845-859.

32. Mineralogy, age and genesis of apatite-dolomite ores at the Seligdar apatite deposit (Central Aldan, Russia) / I.R. Prokopyev, A.G. Doroshkevich, A.V. Ponomarchuk, S.A. Sergeev // Ore Geology Reviews. - 2017. - V. 81. - P. 296-308.

Поступила 13.03.2018 2. 


\section{Информация об авторах}

Широносова Г.П., кандидат геолого-минералогических наук, старший научный сотрудник лаборатории щелочного магматизма и рудообразования Института геологии и минералогии им. В.С. Соболева Сибирского отделения Российской Академии наук.

Прокопьев И.Р., кандидат геолого-минералогических наук, научный сотрудник лаборатории щелочного магматизма и рудообразования Института геологии и минералогии им. В.С. Соболева Сибирского отделения Российской Академии наук; старший преподаватель кафедры геологии рудных месторождений Геолого-геофизического факультета Новосибирского государственного университета. 
UDC 550.41

\title{
COEFFICIENTS OF DISTRIBUTION OF REE+Y BETWEEN MINERALS AND COOLING RICH SULFATE FLUID (THERMODYNAMIC MODELING)
}

\author{
Galina P. Shironosova', \\ shiron@igm.nsc.ru \\ llya R. Prokopyev ${ }^{1,2}$, \\ prokop@igm.nsc.ru \\ 1 V.S. Sobolev Institute of Geology and Mineralogy SB RAS, \\ 3, academician Koptyug avenue, Novosibirsk, 630090, Russia. \\ ${ }^{2}$ Novosibirsk State University, \\ 2, Pirogov street, Novosibirsk, 630090, Russia.
}

The relevance of the work is caused by the fact that the study of the coefficients of $R E E+Y$ distribution between the minerals-concentrators of these elements and between minerals and sulfate fluids in various alkaline and weakly acidic systems makes it possible to obtain the missing parameters necessary for modeling crystallization and ore formation within the carbonatite ore-magmatic systems. To determine the mechanisms of concentrating ore components, the most important is the identification of the main and minor mineralsconcentrators of rare elements.

The main aim of the study is to estimate the distribution coefficients of lanthanides $+Y$ between REE-bearing minerals and between these minerals and the hydrothermal fluid in equilibrium with them in weakly acidic and weakly alkaline conditions at the temperature of $500-100{ }^{\circ} \mathrm{C}$ and pressure of $2000-125$ bar.

The methods: the thermodynamic modeling of monazite and calcite interaction with hydrothermal fluids using the HCh software computer code (developer Yu.V. Shvarov); minimization of Gibbs free energy of the system (Gibbs program) together with UNITHERM thermodynamic database were used to determine the equilibrium state in the program algorithm.

The results. It is shown that the coefficients of REE+Y distribution between minerals are mostly independent on the acid-alkaline mineral formation environment. The acidity-alkalinity of fluids has a noticeable effect only on distribution of REE between fluorite and fluorapatite. The main influence on REE fractionation is exerted by temperature and the parameters associated with it. Only for the monazite/REE-fluorite pair, the decrease in temperature promotes the increase in values of the distribution coefficients, i. e. the entry of REE into monazite. In pairs monazite/REE-fluorapatite, xenotime/REE-fluorapatite, and in acidic conditions in the REE-fluorite/REE-fluorapatite pair, decrease in temperature is accompanied by decrease in the distribution coefficients and facilitates some enrichment of fluorapatite with rare earths. Kd mineral/fluid for monazite, xenotime and REE-fluorite is above one and this means that when the equilibrium fluid is cooled, REE+Y predominantly concentrates in these minerals.

Key words:

$R E E$, monazite, xenotime, REE-fluorapatite, REE-fluorite, REE $+Y$ distribution coefficients, oxidized fluid, thermodynamic modeling.

The studies were supported by the research project of the Institute of Geology and Mineralogy SB RAS, no. 0330-2016-0002.

\section{REFERENCES}

1. Andersen A.K., Clark J.G., Larson P.B., Donovan J.J., REE fractionation, mineral speciation, and supergene enrichment of the Bear Lodge carbonatites, Wyoming. Ore Geology Reviews, 2017, vol. 89 , pp. $780-807$.

2. Janots E., Bernier F., Brunet F., Munoz M., Trcera N., Berger A., Lanson M. Ce (III) and Ce (IV) (re) distribution and fractionation in a laterite profile from Madagascar: Insights from in situ XANES spectroscopy at the Ce LIII-edge. Geochim. et cosmochim. Acta, 2015, vol. 153, pp. 134-148.

3. Smythe D.J., Brenan J.M. Cerium oxidation state in silicate melts: Combined $\mathrm{fO}_{2}$, temperature and compositional effects. $\mathrm{Ge}$ ochim. et cosmochim. Acta, 2015, vol. 170, pp. 173-187.

4. Kohler S.J., Harouiya N., Chairat C., Oelkers E.H. Experimental studies of REE fractionation during water-mineral interactions: $\mathrm{REE}$ release rates during apatite dissolution from $\mathrm{pH} 2.8$ to 9.2 . Chemical Geology, 2005, vol. 222, pp. 168-182.

5. Li H., Hermann J. The effect of fluorine and chlorine on trace element partitioning between apatite and sediment melt at subduction zone conditions. Chemical Geology, 2017, vol. 473, pp. $55-73$.

6. Liang Y., Liu B. Simple Models for Disequilibrium Fractional Melting and Batch Melting with Application REE fractionation in abyssal peridotites. Geochim. et cosmochim. Acta, 2016, vol. 173, pp. 181-197.

7. Wohlers A., Wood B.J. Uranium, thorium and REE partitioning into sulfide liquids: Implications for reduced S-rich bodies. Geochim. et cosmochim. Acta, 2017, vol. 205, pp. 226-244.

8. Toyama K., Terakado Y., Experimental study of rare earth element partitioning between calcite and sodium chloride solution at room temperature and pressure. Geochem. J., 2014, vol. 48, pp.463-477.

9. Curti E., Kulik D.A., Tits J. Solid solutions of trace Eu (III) in calcite: Thermodynamic evaluation of experimental data over a wide range of $\mathrm{pH}$ and $\mathrm{pCO}_{2}$. Geochim. et cosmochim. Acta, 2005, vol. 69 , pp. 1721-1737.

10. Lakshtanov L.Z., Stipp S.L.S. Experimental study of europium (III) coprecipitation with calcite. Geochim. et cosmochim. Acta, 2004, vol. 68, pp. 819-827.

11. Karato S. Physical basis of trace element partitioning: a review. American Mineralogist, 2016, vol. 101, pp. 2577-2593.

12. Suvorova L.F., Kaneva E.V., Lipko S.V., Tauson V.L., Taroev V.K., Kashaev A.A. REE distribution between ferrous mica, K-feldspar and kalsilite at $500{ }^{\circ} \mathrm{C}$ and $1 \mathrm{~kb}$ in $\mathrm{KOH}$ solution. Experiment in Geosciences, 2017, vol. 23, no. 1, pp. 104-107.

13. Nandedkar R.H., Hurlimann N., Ulmer P., Muntener 0. Amphibole-melt trace element partitioning of fractionating calc-alkali- 
ne magmas in the lower crust: an experimental study. Contrib $\mathrm{Mi}$ neral Petrol., 2016, vol. 171:71.

14. Zajacz Z. The effect of melt composition on the partitioning of oxidized sulfur between silicate melts and magmatic volatiles. Geochim. et cosmochim. Acta, 2015, vol. 158, pp. 223-244.

15. Shironosova G.P., Kolonin G.R. Thermodynamic Modeling of REE Partitioning between Monazite, Fluorite, and Apatite. Doklady Earth Sciences, 2013, vol. 450, P. 2, pp. 628-632. In Rus.

16. Voigt M., Mavromatis V., Oelkers E.H. The experimental determination of REE partition coefficients in the water-calcite system. Chemical Geology, 2017, vol. 462, pp. 30-43.

17. Shironosova G.P., Prokopyev I.R. REE+Y behavior in fluoridechloride-sulphide-sulphate-carbonate environment at hydrothermal stages of alkaline magmatic complexes according to thermodynamic modeling. Bulletin of the Tomsk Polytechnic University. Geo Assets Engineering, 2017, vol. 328, no. 12, pp. 75-83. In Rus.

18. Shvarov Yu.V. HCh: New potentialities for the thermodynamic simulation of geochemical systems offered by windows. Geochemistry International, 2008, vol. 46, no. 8, pp. 834-839. In Rus.

19. Shvarov Yu.V., Bastrakov E. HCh: a Software Package for Geochemical Equilibrium Modeling: User's Guide (AGSO RECORD, 1999). Canberra, Dept. Industry, Australian Geol. Surv. Org., Sci. Resour., 1999. 57 p.

20. Xu Ch., Kynicky J., Chakhmouradian A.R., Li X., Song W. A case example of the importance of multi-analytical approach in deciphering carbonatite petrogenesis in South Qinling orogen: Miaoya rare-metal deposit, central China. Lithos, 2015, vol. 227, pp. 107-121.

21. Xu Ch., Kynicky J., Chakhmouradian A.R., Campbell I.H., Allen Ch.M. Traceelement modeling of the magmatic evolution of rare-earth-rich carbonatite from the Miaoya deposit, Central China. Lithos, 2010, vol. 118, pp. 145-155.

22. Zaitzev A.N., Willaims T., Jeffries T., Strekopytov S., Moutte J., Ivashchenkova 0.V., Spratt J., Petrov S.V., Wall F., Seltmann R., Borozdin A.P. Rare earth elements in phoscorites and carbonatites of the Devonian Kola Alkaline Province, Russia: examples from Kovdor, Khibina, Vuoriyarvi and Turiy Mys complexes. Ore Geology Reviews, 2014, vol. 61, pp. 204-225.

23. Doroshkevich A.G., Veksler I.V., Klemd R., Khromova E.A., Izbrodin I.A. Trace-element composition of minerals and rocks in the Belaya Zima carbonatite complex (Russia): Implications for the mechanisms of magma evolution and carbonatite formation. Lithos, 2017, vol. 284-285, pp. 91-108.

24. Harlov D.E., Wirth R., Förster H.-J. An experimental study of dissolution-reprecipitation in fluorapatite: fluid infiltration and the formation of monazite. Contributions to Mineralogy and Petrology, 2005, vol. 150, pp. 268-286

25. Harlov D.E., Förster H-J. Fluid induced nucleation of (Y+REE)phosphate minerals within apatite: Nature and experiment Part II. Fluorapatite. American Mineralogist, 2003, vol. 88, pp. 1209-1229.

26. Williams-Jones A.E., Migdisov A.A., Samson I.M. Hydrothermal Mobilisation of the Rare Earth Elements - a Tale of «Ceria» and «Yttria». Elements, 2012, vol. 8 (5), pp. 355-360.

27. Tropper P., Manning C.E., Harlov D.E. Solubility of $\mathrm{CePO}_{4}$ monazite and $\mathrm{YPO}_{4}$ xenotime in $\mathrm{H}_{2} \mathrm{O}$ and $\mathrm{H}_{2} \mathrm{O}-\mathrm{NaCl}$ at $800{ }^{\circ} \mathrm{C}$ and $1 \mathrm{GPa}$ : Implications for REE and Y transport during high-grade metamorphism. Chemical Geology, 2011, vol. 282, pp. 58-66.

28. Tropper P., Manning C.E., Harlov D.E. Experimental determination of $\mathrm{CePO}_{4}$ and $\mathrm{YPO}_{4}$ solubilities in $\mathrm{H}_{2} \mathrm{O}-\mathrm{NaF}$ at $800{ }^{\circ} \mathrm{C}$ and $1 \mathrm{GPa}$ Implications for rare earth element transport in high-grade metamorphic fluids. GeoFluids, 2013, vol. 13, pp. 372-380.

29. Shironosova G.P., Kolonin G.R., Borovikov A.A., Borisenko A.S. Thermodynamic Modeling of REE Behavior in Oxidized Hydrothermal Fluids of High Sulfate Sulfur Concentrations. Doklady Earth Sciences, 2016, vol. 469, P. 2, pp. 855-859. In Rus.

30. Buhn B., Rankin A.H., Schneider J., Dulski P. The nature of orthomagmatic, carbonatitic fluids precipitating REE, Sr-rich fluorite: fluid-inclusion evidence from the Okorusu fluorite deposit, Namibia. Chemical geology, 2002, vol. 186 (1-2), pp. 75-98.

31. Prokopyev I.R., Borisenko A.S., Borovikov A.A., Pavlova G.G. Origin of REE-rich ferrocarbonatites in southern Siberia (Russia): implications based on melt and fluid inclusions. Mineralogy and petrology, 2016, vol. 110 (6), pp. 845-859.

32. Prokopyev I.R., Doroshkevich A.G., Ponomarchuk A.V., Sergeev S.A. Mineralogy, age and genesis of apatite-dolomite ores at the Seligdar apatite deposit (Central Aldan, Russia). Ore Geology Reviews, 2017, vol. 81. pp. 296-308.

Received: 13 March 2018.

\section{Information about the authors}

Galina P. Shironosova, Cand. Sc., senior researcher, V.S. Sobolev Institute of Geology and Mineralogy SB RAS.

Ilya R. Prokopyev, Cand. Sc., researcher, V.S. Sobolev Institute of Geology and Mineralogy SB RAS; senior lecturer, Novosibirsk State University. 